\title{
Postoperatieve anorexie en ileus bij het konijn: een praktijkonderzoek bij electieve chirurgie
}

\author{
Postoperative anorexia and ileus in the rabbit: \\ a practical research in elective surgery
}

\author{
${ }^{1}$ E. Hartings, ${ }^{2}$ K. Hermans, ${ }^{2}$ I. Moeremans, ${ }^{3} \mathrm{~J}$. Dewulf
}

\begin{abstract}
${ }^{1}$ Dierenkliniek Soest, Steenhoffstraat 64, NL-3764-BM, Soest, Nederland
${ }^{2}$ Vakgroep Pathobiologie, Farmacologie en Bijzondere Dieren, Faculteit Diergeneeskunde, Universiteit Gent, Salisburylaan 133, B-9820 Merelbeke, België

${ }^{3}$ Vakgroep Interne Geneeskunde, Voortplanting en Populatiegeneeskunde, Faculteit Diergeneeskunde, Universiteit Gent, Salisburylaan 133, B-9820 Merelbeke, België
\end{abstract}

Katleen.Hermans@UGent.be

AMENVATTING

Anorexie en ileus zijn frequent voorkomende postoperatieve complicaties bij konijnen en zijn potentieel fataal. Risicofactoren, zoals stress en pijn, moeten zoveel mogelijk beperkt of vermeden worden. Om risicofactoren rondom het anesthesieprotocol bij orchidectomie en ovario(hyster)ectomie $(\mathrm{OV}(\mathrm{H}) \mathrm{X})$ beter in beeld te brengen, werd een enquête rondgestuurd naar dierenartsen in België en Nederland. Uit de 209 ingevulde enquêtes bleek het type operatie (orchidectomie versus $\mathrm{OV}(\mathrm{H}) \mathrm{X}$ ) een significante invloed te hebben. Er werden nog twee andere significante verschillen opgemerkt: er was minder vaak ileus bij $\mathrm{OV}(\mathrm{H}) \mathrm{X}$ waarbij butorfanol werd gebruikt en er was vaker anorexie bij $\mathrm{OV}(\mathrm{H}) \mathrm{X}$ waarbij een antidotum werd toegediend. Dit moet echter met de nodige voorzichtigheid geïnterpreteerd worden, aangezien andere studiegerelateerde factoren hierbij een rol gespeeld kunnen hebben. Het is hierbij vermeldenswaardig dat bij het gebruik van buprenorfine - een opioïde waarover in de literatuur tegenstrijdige resultaten te vinden zijn betreffende het al dan niet induceren van gastro-intestinale stase bij konijnen - in de voorliggende studie niet significant vaker ileus werd opgemerkt.

\section{ABSTRACT}

Anorexia and ileus are common postoperative complications in rabbits and can be fatal if left untreated. Risk factors, like stress and pain, need to be minimized or avoided as much as possible. To get an insight into potential risk factors related to the anesthetic protocol for orchidectomy and ovario(hyster)ectomy $(\mathrm{OV}(\mathrm{H}) \mathrm{X})$, a questionnaire was sent to veterinarians in Belgium and the Netherlands. Based on 209 answered questionnaires, a significant difference in the development of anorexia and ileus could be seen depending on the type of surgery (less in orchidectomy than in $\mathrm{OV}(\mathrm{H}) \mathrm{X}$ ). Two other significant differences were noted: ovario(hyster)ectomized rabbits less frequently developed ileus when butorphanol was used, and more frequently developed anorexia when an antidote was used. This must however be interpreted carefully, since other study-related factors may have played a role. When considering whether or not buprenorphine - an opioid drug for which contradictory results have been reported in the literature - induces gastrointestinal stasis in rabbits, it is noteworthy that in this study, ileus was not reported to be a significant, more frequently noted side effect. 


\section{INLEIDING}

Naast de bekende anesthetische risico's, i.e. cardiorespiratoire depressie en hypothermie, die ook bij honden en katten voorkomen, is postoperatieve ileus bij het konijn een ernstige complicatie (Brodbelt, 2006; Longley, 2008). In een studie van Lee et al. (2018) ontwikkelde $38 \%$ van de onderzochte konijnen perianesthetisch gastro-intestinale complicaties. Inadequaat behandelde ileus kan leiden tot levensbedreigende dysbacteriose, hepatische lipidose en ketoacidose (Harcourt-Brown, 2013; Harcourt-Brown, 2014; Varga, 2014b).

Er zijn verschillende redenen waarom anesthesie en chirurgie kunnen leiden tot anorexie en ileus. Pijn en stress activeren het sympathisch zenuwstelsel en de catecholaminevrijstelling, met een reductie van de darmmotiliteit tot gevolg (Johnson-Delaney en Harcourt-Brown, 2013; Varga, 2014b). Uiteraard zijn de manier waarop de chirurgie wordt uitgevoerd, de ervaring van de chirurg, het type hechtmateriaal, etc. van belang, doch specifiek voor konijnen dient men ook aandacht te schenken aan bepaalde factoren tijdens de recovery om stress en het ontstaan van anorexie en ileus te minimaliseren: een rustige recovery- en hospitalisatieruimte afgescheiden van andere diersoorten (Johnson-Delaney en Harcourt-Brown, 2013; Eatwell, 2014), aanwezigheid van de partner (JohnsonDelaney en Harcourt-Brown, 2013) en dwangvoeding en prokinetica bij anorexie en/of ileus (JohnsonDelaney en Harcourt-Brown, 2013; Eatwell, 2014; Varga, 2014c). Adequate pijnherkenning, -bestrijding en vooral -preventie zijn primordiaal (Longley, 2008; Johnson-Delaney en Harcourt-Brown, 2013; Bament en Goodman, 2014; Eatwell, 2014; Varga, 2014c).

Het al dan niet ontstaan van ileus wordt beïnvloed door verschillende componenten van het anesthesieprotocol. Ontoereikende analgesie veroorzaakt pijn en stress. Het is belangrijk om reeds vóór de aanvang van de chirurgie analgesie toe te passen, om te voorkomen dat het zenuwstelsel wordt gesensibiliseerd ("neuronal wind-up") en om zo postoperatieve pijn te reduceren (Lichtenberger en Ko, 2007; Johnson-Delaney en Harcourt-Brown, 2013). Bovendien kan een sterkere analgesie bekomen worden door gebruik te maken van meerdere producten uit verschillende klassen: multimodale analgesie (bijvoorbeeld een opioïde met een NSAID) (Lichtenberger en Ko, 2007). Daarnaast is van sommige producten bekend dat zij inwerken op het gastro-intestinale stelsel (Grint, 2013; JohnsonDelaney en Harcourt-Brown, 2013).

Bij konijnen kunnen verschillende producten gebruikt worden als premedicatie, inductie en onderhoud: de benzodiazepines midazolam en diazepam, (dex)medetomidine, opioïden (onder andere morfine, fentanyl, buprenorfine en butorfanol), ketamine, alfaxalone, propofol, etomidaat en volatiele anesthetica (zoals iso- en sevofluraan) (Longley, 2008; Wenger,
2012; Grint, 2013; Eatwell, 2014; Varga, 2014a). Een frequent gebruikte combinatie is ketamine en (dex) medetomidine, die een chirurgische anesthesie van twintig tot dertig minuten en een recoverytijd van anderhalf tot drie uur geeft (Longley, 2008). Een van de nadelen van (dex)medetomidine is dat het naast cardiorespiratoire effecten een reductie van de gastro-intestinale motiliteit veroorzaakt (Longley, 2008; Grint, 2013).

Lokale anesthetica, zoals lidocaïne en bupivacaine, kunnen gebruikt worden om te zorgen voor dosisreductie (multimodale analgesie) en dragen bij tot een reductie van postoperatieve pijn (Johnson-Delaney en Harcourt-Brown, 2013; Eatwell, 2014).

Omtrent opioïden zijn verschillende tegenstrijdigheden te vinden in de literatuur. Interactie met de muen kappa-receptoren zorgt voor analgesie/sedatie/anesthesie peri- en postoperatief. Deze receptoren zijn ook aanwezig in het gastro-intestinale stelsel. Interactie op dit niveau kan leiden tot een reductie van de gastro-intestinale motiliteit (Barter, 2011; JohnsonDelaney en Harcourt-Brown, 2013; Eatwell, 2014; Varga, 2014a). In sommige onderzoeken naar de invloed van buprenorfine op de gastro-intestinale motiliteit bij konijnen wordt dit bevestigd (Martin-Flores et al., 2017; Schnellbacher et al., 2017) terwijl het in andere studies tegengesproken wordt (Cooper et al., 2009; Goldschlager et al., 2013; Deflers et al., 2018).

De NSAID's carprofen en meloxicam worden frequent gebruikt voor postoperatieve pijnbestrijding bij konijnen en werken goed tegen milde of matige pijn (Wenger, 2012; Eatwell, 2014). De auteurs vonden geen informatie in de literatuur omtrent een mogelijke invloed van deze middelen op de gastro-intestinale motiliteit.

Er is nog weinig bekend over het effect van het type operatie en het anesthesieprotocol op het ontwikkelen van postoperatieve anorexie en ileus bij het konijn, alhoewel dit toch ernstige complicaties zijn. Het doel van dit onderzoek was om na te gaan of er binnen een anesthesieprotocol voor orchidectomie en ovario(hyster)ectomie $(\mathrm{OV}(\mathrm{H}) \mathrm{X})$ bepaalde risicofactoren zijn die een grotere kans op postoperatieve anorexie en ileus geven.

\section{MATERIAAL EN METHODEN}

Via Google Forms werd een vragenlijst opgesteld en elektronisch verdeeld onder dierenartsen in Vlaanderen en Nederland. Hiermee werd per type operatie (orchidectomie, ovariëctomie of ovariohysterectomie) nagegaan welk anesthesie- en analgesieprotocol werd gebruikt. Daarnaast werd het voorkomen van ileus en anorexie 24 uur postoperatief gedocumenteerd.

De dierenartsen werden via verschillende wegen gecontacteerd. De eerste zes dierenartsen waren bekend bij de auteurs en werden via mail gecontacteerd. 
Vervolgens werden via het Dierenartsen Dashboard 695 dierenartsen uit Nederland via mail gecontacteerd en werd voor de Vlaamse dierenartsen een oproep geplaatst op de SAVAB-facebookgroep met circa 1600 leden. Uiteindelijk hebben 67 dierenartsen, met verschillende graad van ervaring met konijnen, aangegeven te willen deelnemen aan het onderzoek en hebben zij een of meerdere vragenlijsten ingevuld.

De enquête bevatte vragen over operatietype en -duur, de leeftijd van het dier, het al dan niet aanwezig zijn van obesitas, de gebruikte anesthesieproducten en hun concentratie voor inductie en onderhoud, het gebruik van een antidotum, het gebruik van extra analgetica inclusief de concentratie, het preventief gebruik van prokinetica, de preventie van hypothermie, het al dan niet (preventief) dwangvoeren en tenslotte, na 24 uur, de eetlust (uitkomst 1) en de fecesproductie (uitkomst 2). De eetlust, uitkomst 1, werd als normaal bevonden als het dier een goede eetlust had en als abnormaal als de eetlust verminderd of afwezig was. De fecesproductie, uitkomst 2 , werd als normaal beschouwd als het dier een normale hoeveelheid en vorm van keutels produceerde en als abnormaal beschouwd als de keutels kleiner van vorm of een minder aantal dan normaal waren. De abnormale eetlust werd hierna (partiële) anorexie genoemd en de afwijkende feces werd gereduceerde gastro-intestinale motiliteit of ileus genoemd.

Voor de data-analyse werd voor elk van de potentiele risicofactoren nagegaan in hoeverre ze een invloed hadden op het al dan niet voorkomen van anorexie en ileus. De analyse gebeurde aan de hand van chikwadraattest (Pearson Chi Square) en logistische regressie via SPSS 25.0 en bij kleinere groepen dieren met behulp van de Fisher's exact test. Het gebruikte significantieniveau was 0,05 .

\section{RESULTATEN}

In totaal werden 216 vragenlijsten ingevuld door 67 deelnemende dierenartsen. Sommigen daarvan hebben meerdere ingevulde vragenlijsten ingediend. Het reactiepercentage was iets minder dan 3\%. Hiervan konden 209 vragenlijsten gebruikt worden voor analyse. De operatietypes waren orchidectomie bij 105 konijnen en ovariëctomie of ovariohysterectomie bij 104 dieren (deze twee laatste types werden samengevoegd voor het analyseren van de resultaten). Voor wat betreft orchidectomie was de eetlust van alle 105 dieren en de fecesproductie van 97 dieren 24 uur postoperatief bekend. Voor wat $\mathrm{OV}(\mathrm{H}) \mathrm{X}$ betreft was de eetlust van alle 104 dieren en de fecesproductie van 95 dieren 24 uur postoperatief bekend.

Ongeveer de helft van de konijnen (56 rammelaars en 60 voedsters) was tussen de vijf en twaalf maanden oud toen ze orchidectomie of $\mathrm{OV}(\mathrm{H}) \mathrm{X}$ ondergingen. Een kwart van de rammelaars (26) zat in de leeftijdscategorie nul tot vier maanden en een re- latief groot aantal voedsters (42\%) was tussen één en vier jaar oud.

\section{Gebruikte anesthetica en analgetica}

De combinatie ketamine met (dex)medetomidine werd het frequentst gebruikt voor inductie van de anesthesie (bij $88 \%$ van de $\mathrm{OV}(\mathrm{H}) \mathrm{X}$ en bij $80 \%$ van de orchidectomieën). Andere anesthesieprotocollen voor inductie (met midazolam, isofluraan, xylazine) werden weinig gebruikt. Voor onderhoud van de anesthesie werd voornamelijk isofluraan (bij 57\% van de $\mathrm{OV}(\mathrm{H}) \mathrm{X}$ en bij $45 \%$ van de orchidectomieën) gebruikt, of werd geen extra product voor onderhoud toegediend (bij 40\% van de $\mathrm{OV}(\mathrm{H}) \mathrm{X}$ en $51 \%$ van de orchidectomieën). Af en toe werden injectie-anesthetica intraoperatief bijgegeven voor onderhoud van de anesthesie (bij 3\% van de $\mathrm{OV}(\mathrm{H}) \mathrm{X}$ en $4 \%$ van de orchidectomieën).

Voor analgesie werden voornamelijk NSAID's gebruikt, 1 . solo bij $38 \%$ van de voedsters en $61 \%$ van de rammelaars, 2. al dan niet in combinatie met buprenorfine bij $45 \%$ van de voedsters en $15 \%$ van de rammelaars, 3 . lokale anesthesie bij $2 \%$ van de voedsters en $10 \%$ van de rammelaars en 4 . butorfanol bij $13 \%$ van de voedsters en $9 \%$ van de rammelaars. In zeldzame gevallen werd een andere combinatie of een ander product (methadon) gebruikt bij $2 \%$ van de voedsters en $5 \%$ van de rammelaars.

\section{Prokinetica, hypothermie en dwangvoeren}

Aan $35 \%$ van de voedsters en aan $22 \%$ van de rammelaars werden preventief prokinetica toegediend. Ter preventie van hypothermie werden verschillende maatregelen toegepast. Het vaakst werd een warmtematje gebruikt (in 64\% van de gevallen). Verder werden couveuses $(16 \%)$, warmtelampen $(15 \%)$ en warmtekruiken (9\%) gebruikt. Daarnaast werden nog diverse andere maatregelen (dekens, warmtezakjes) genomen. Dwangvoeren werd na OV(H)X vaker gedaan dan na orchidectomie wegens onvoldoende zelfstandig eten $(22 \%$ na $\mathrm{OV}(\mathrm{H}) \mathrm{X}$ versus $5 \%$ na orchidectomie). Preventief dwangvoeren werd bij $20 \%$ van de voedsters en $15 \%$ van de rammelaars toegepast. Achtenvijftig procent van de konijnen $\operatorname{die} \mathrm{OV}(\mathrm{H}) \mathrm{X}$ en $80 \%$ van de konijnen die orchidectomie ondergingen, werden niet gedwangvoerd.

\section{Invloed van het operatietype op eetlust en feces- productie}

Er was een significant verschil $(\mathrm{P}<0,01)$ naar gelang het operatietype zowel voor eetlust als fecesproductie 24 uur postoperatief. (Partiële) anorexie werd bij $17 \%$ van de konijnen die orchidectomie ondergingen en bij 56\% die $\mathrm{OV}(\mathrm{H}) \mathrm{X}$ ondergingen, waargenomen. Ileus kwam voor bij $18 \%$ van de rammelaars en $48 \%$ van de voedsters. 
Invloed van het antidotum op eetlust en fecesproductie

Van de 104 voedsters die $\mathrm{OV}(\mathrm{H}) \mathrm{X}$ ondergingen, kreeg 86\% een antidotum (atipamezole). Bij de rammelaars die orchidectomie ondergingen, was dit $70 \%$. Er was een significant verschil $(\mathrm{P}=0,02)$ te zien in postoperatieve eetlust tussen voedsters die geen antidotum hadden gekregen en degene die dat wel hadden gekregen: 61\% van de voedsters had een verminderde eetlust wanneer een antidotum werd gebruikt versus $27 \%$ van de voedsters die geen antidotum had gekregen. Er waren geen significante verschillen in fecesproductie bij de voedsters en geen significante verschillen in postoperatieve eetlust noch in fecesproductie bij de rammelaars.

Invloed van gebruikte analgetica op eetlust en fecesproductie

Er was een significant verschil $(\mathrm{P}=0,02)$ in fecesproductie tussen de groep voedsters die wel (16\%) en die geen $(84 \%)$ butorfanol toegediend kreeg. Voedsters die butorfanol hadden gekregen, hadden minder vaak een afwijkende fecesproductie (20\% versus 54\% bij voedsters die geen butorfanol werden toegediend). Er waren geen significante verschillen in eetlust na $\mathrm{OV}(\mathrm{H}) \mathrm{X}$ en geen significante verschillen in eetlust noch in fecesproductie na orchidectomie. Bij de andere gebruikte analgetica (lokale anesthesie en buprenorfine) werden evenmin significante verschillen waargenomen.

NSAIDs werden aan 97\% van de dieren toegediend, waardoor geen effect van het gebruik hiervan op eetlust en fecesproductie kon worden bestudeerd.

\section{Invloed van overige factoren op eetlust en feces- productie}

Bij alle overige factoren werden er geen significante effecten gezien op postoperatieve eetlust en fecesproductie. Dit geldt dus voor de invloed van leeftijd, obesitas, de gebruikte methoden voor inductie en onderhoud, het preventief gebruik van prokinetica en het preventief dwangvoeren.

\section{DISCUSSIE}

Door de snel en gemakkelijk in te vullen vragenlijst heeft een voldoende aantal dierenartsen (67) deelgenomen, waardoor representatieve onderzoeksresultaten konden verzameld worden. Dankzij deze studie is er meer inzicht in de anesthesieprotocollen die momenteel gebruikt worden voor orchidectomie en $\mathrm{OV}(\mathrm{H}) \mathrm{X}$ bij konijnen en in het voorkomen van postoperatieve anorexie en ileus in België en Nederland. De hospitalisatieomstandigheden waarin het dier opgenomen wordt, kunnen naast het anesthesie- protocol een belangrijke invloed hebben op de ontwikkeling van postoperatieve anorexie en ileus. Deze werden echter bewust niet in deze vragenlijst opgenomen, omdat de enquête dermate uitgebreid zou worden, waardoor de bereidwilligheid van de deelnemende dierenartsen zou kunnen afnemen. Bovendien wordt door de auteurs aangenomen dat, gezien in totaal 67 dierenartsen deelnamen, de invloed van eventuele specifieke hospitalisatieomstandigheden in één of meerdere praktijken relatief beperkt was. Echter, elke dierenarts kon anoniem en onbeperkt vragenlijsten invullen. Derhalve is het mogelijk dat een dierenarts met een specifiek anesthesieprotocol (bijvoorbeeld het gebruik van butorfanol) veel vragenlijsten heeft ingevuld, en op die manier ook de dierenartsenpraktijkgebonden factoren, zoals hospitalisatieomstandigheden, ervaring van de chirurg, etc., mee opgenomen zijn bij het beoordelen van de risicofactor. Tot slot is het mogelijk dat sommige antwoordmogelijkheden door de deelnemende dierenartsen op verschillende manier geïnterpreteerd werden, zoals bijvoorbeeld 'preventief dwangvoeren' (wanneer is dwangvoeren preventief?) en de uitkomsten voor wat betreft de eetlust en fecesproductie (wanneer wordt dit als verminderd of afwijkend gezien?).

De waargenomen verminderde of zelfs afwezige eetlust en gereduceerde gastro-intestinale motiliteit stroken met de gegevens uit de literatuur (Longley 2008; Oglesbee en Jenkins, 2012). De resultaten van deze enquête betreffende (partiële) anorexie en ileus zijn gerelateerd, maar werden niet per se tegelijkertijd opgemerkt (Harcourt-Brown, 2014).

Zoals verwacht was er een duidelijk aantoonbaar verband tussen het type operatie en het voorkomen van (partiële) anorexie en ileus. Dit kan verklaard worden door de invasiviteit, de langere operatieduur en de manipulatie van de darmen bij sterilisatie, waardoor de kans op hypothermie en andere neveneffecten van de anesthesie toeneemt (Brodbelt, 2006; HarcourtBrown, 2013a; Saunders, 2013).

Tegen de verwachting in ontwikkelden voedsters die een antidotum (atipamezole) toegediend kregen vaker een verminderde eetlust dan voedsters die dit niet hadden gekregen. Mogelijk komt dit doordat een deel van de analgesie opgeheven wordt, of dat het versneld ontwaken zonder voldoende analgesie voor een stressreactie zorgt (Longley, 2008). Het is niet bekend op welk tijdstip het antidotum werd toegediend en of dit dus kort of lang na inductie/chirurgie was. De reden van de toediening van het antidotum is ook onbekend: werd het standaard direct na chirurgie toegediend, of pas na lange recovery wegens niet goed ontwaken? De opzet van het voorliggend onderzoek kan over de oorzaak geen duidelijkheid geven. Bij de rammelaars is dit verschil niet te zien, maar orchidectomie is dan ook een minder invasieve ingreep dan $\mathrm{OV}(\mathrm{H}) \mathrm{X}$. Het kan ook een onterecht of toevallig significant verschil zijn, aangezien de groep voedsters die geen antidotum had gekregen, relatief klein was (14\%). Bij de ram- 
melaars was er een betere verdeling tussen de groep die wel en de groep die geen antidotum toegediend hadden gekregen.

Een andere opvallende uitkomst is de invloed van butorfanol op de gastro-intestinale motiliteit. Bij $\mathrm{OV}(\mathrm{H}) \mathrm{X}$ waren er significant meer konijnen met ileus 24 uur postoperatief wanneer ze geen butorfanol hadden gekregen. Bij orchidectomie werd dit verschil niet gezien. Voor beide types operatie was de groep dieren die butorfanol had gekregen, zeer klein (14\% van de voedsters en $8 \%$ van de rammelaars). Dit verlaagt daarom de betrouwbaarheid van dit specifieke resultaat. Er is immers een reële kans dat deze dieren door dezelfde dierenarts of door een kleine groep dierenartsen werden geopereerd, wat een bias in de resultaten kan teweeg gebracht hebben.

Vanwege tegenstrijdige resultaten in de literatuur was het gebruik van buprenorfine een interessante factor. Uit de resultaten is geen significant verschil gebleken in de postoperatieve eetlust en gastro-intestinale motiliteit tussen de groepen die met en zonder buprenorfine werden behandeld. Daaruit kan geconcludeerd worden dat het gebruik van buprenorfine in het anesthesieprotocol geen verhoogde kans op ileus met zich heeft meegebracht in deze studie.

Van medetomidine en dexmedetomidine is bekend dat ze een reductie van de gastro-intestinale motiliteit kunnen veroorzaken (Grint, 2013). Dit kon in de huidige studie niet worden bevestigd, allicht omdat er onvoldoende dieren waren waarbij geen medetomidine of dexmedetomidine werd toegediend (slechts $17 \%$ bij orchidectomie en $10 \%$ bij $\mathrm{OV}(\mathrm{H}) \mathrm{X})$. Medetomidine en dexmedetomidine werden in de voorliggende studie als afzonderlijke risicofactoren gemeten en aldus vooral met elkaar vergeleken omdat ze beide veelvuldig gebruikt werden. Tussen deze middelen werd geen verschil gezien, wat strookt met de literatuur dat ze beide een negatief effect op het gastrointestinale stelsel kunnen hebben (Grint, 2013). Andere factoren waar geen significante verschillen gezien werden, waren obesitas, leeftijd en het gebruik van lokale anesthetica. Mogelijk is dit een gevolg van het feit dat er onvoldoende obese/oudere dieren en dieren waarbij lokale anesthesie werd gebruikt, aanwezig waren in de studie.

Er werd geen significant effect van het preventief gebruik van prokinetica waargenomen. Dit kan mede het gevolg zijn van het tijdstip van toediening. Indien dergelijke omstandigheden, zoals tijdstip van toediening, product, dosering, etc., steeds dezelfde zijn, dan betekent dit dat het preventief toedienen van prokinetica postoperatieve ileus niet voorkomt.

\section{CONCLUSIE}

Dankzij dit onderzoek werden gebruikte anesthesieprotocollen bij orchidectomie en $\mathrm{OV}(\mathrm{H}) \mathrm{X}$ bij het konijn in België en Nederland in kaart gebracht. Uit de studie blijkt dat postoperatieve anorexie en ileus hier nog regelmatig voorkomen. Het type operatie speelt hierbij een belangrijke rol. Uit het onderzoek blijkt dat konijnen die $\mathrm{OV}(\mathrm{H}) \mathrm{X}$ hadden ondergaan, significant vaker (partiële) anorexie en een gereduceerde gastro-intestinale motiliteit of ileus ontwikkelden. Het gebruik van buprenorfine gaf daarentegen geen hoger risico op postoperatieve ileus. Butorfanol en het toedienen van antidotum bleken een invloed te hebben, maar moeten met de nodige voorzichtigheid geïnterpreteerd worden; evenzeer geldt voorzichtige interpretatie van factoren die geen invloed lijken te hebben.

Uit dit onderzoek blijkt eveneens dat er geen van de gebruikte anesthesieprotocollen beter vermeden kan worden in verband met postoperatieve anorexie en ileus.

\section{DANKBETUIGING}

De auteurs willen de talrijke Belgische en Nederlandse dierenartsen die de vragenlijsten (meerdere malen) ingevuld hebben, hartelijk danken voor hun kostbare tijd en moeite. Zonder hen was dit onderzoek nooit tot stand kunnen komen.

\section{LITERATUUR}

Bament W., Goodman G. (2014). General nursing care and hospital management. In: Meredith, A., Lord, B. (editors). BSAVA Manual of Rabbit Medicine. British Small Animal Veterinary Association, Gloucester, UK, p. 114122.

Barter L.S. (2011). Rabbit analgesia. Veterinary Clinics of North America: Exotic Animal Practice 14, 93-104.

Brodbelt D.C. (2006). The Confidential Enquiry into Perioperative Small Animal Fatalities. Thesis, Doctor of Philosophy, Royal Veterinary College, University of London, UK.

Cooper C.S., Metcalf-Pate K.A., Barat C.E., Cook J.A., Scorpio D.G. (2009). Comparison of side effects between buprenorphine and meloxicam used postoperatively in Dutch belted rabbits (Oryctolagus cuniculus). Journal of the American Association for Laboratory Animal Science 48, 279-285.

Deflers H., Gandar F., Bolen G., Farnir F., Marlier D. (2018). Influence of a single dose of buprenorphine on rabbit (Oryctolagus cuniculus) gastrointestinal motility. Veterinary Anaesthesia and Analgesia 45, 510-519.

Eatwell K. (2014). Analgesia, sedation and anaesthesia. In: Meredith A., Lord B. (editors). BSAVA Manual of Rabbit Medicine. British Small Animal Veterinary Association, Gloucester, UK, p. 138-159.

Goldschlager, G.B., Gillespie, V.L., Palme, R., Baxter, M.G. (2013). Effects of multimodal analgesia with lowdose buprenorphine and meloxicam on fecal glucocorticoid metabolites after surgery in New Zealand White Rabbits (Oryctolagus cuniculus). Journal of the American Association for Laboratory Animal Science 52, 571-576. 
Grint N. (2013). Anaesthesia. In: Harcourt-Brown F., Chitty J. (editors). BSAVA Manual of Rabbit Surgery, Dentistry and Imaging. British Small Animal Veterinary Association, Gloucester, UK, p. 1-18.

Harcourt-Brown F. (2013). Gastric dilation and intestinal obstruction. In: Harcourt-Brown F., Chitty J. (editors). BSAVA Manual of Rabbit Surgery, Dentistry and Imaging. British Small Animal Veterinary Association, Gloucester, UK, p.172-174, 182-183.

Harcourt-Brown F. (2014). Digestive system disease. In: Meredith A., Lord B. (editors). BSAVA Manual of Rabbit Medicine. British Small Animal Veterinary Association, Gloucester, UK, p. 168-177, 185-186.

Johnson-Delaney C.A., Harcourt-Brown F. (2013). Analgesia and postoperative care. In: Harcourt-Brown F., Chitty J. (editors). BSAVA Manual of Rabbit Surgery, Dentistry and Imaging. British Small Animal Veterinary Association, Gloucester, UK, p. 26-36.

Lee H.W., Machin H., Adami C. (2018). Peri-anaesthetic mortality and nonfatal gastrointestinal complications in pet rabbits: a retrospective study on 210 cases. Veterinary Anaesthesia and Analgesia 45, 520-528.

Lichtenberger M., Ko J. (2007). Anesthesia and analgesia for small mammals and birds. Veterinary Clinics of North America: Exotic Animal Practice 10, 293-315.

Longley L. (2008). Rabbit anaesthesia. In: Anaesthesia of Exotic Pets. Saunders Elsevier, London, UK, p. 36-58.

Martin-Flores M., Singh B., Walsh C.A., Brooks E.P., Taylor L.C., Mitchell L.M. (2017). Effects of buprenorphine, methylnaltrexone, and their combination on gastrointestinal transit in healthy New Zealand White rabbits. Journal of the American Association for Laboratory Animal Science 56, 155-159.

Oglesbee B.L., Jenkins J.R. (2012). Gastrointestinal diseases. In: Quesenberry K.E., Carpenter J.W. (editors). Ferrets, Rabbits and Rodents: Clinical Medicine and Surgery. Third edition, Saunders Elsevier, St. Louis, MO, USA, p. 193-196.
Saunders R. (2013). Exploratory laparotomy. In: HarcourtBrown F., Chitty J. (editors). BSAVA Manual of Rabbit Surgery, Dentistry and Imaging. British Small Animal Veterinary Association, Gloucester, UK, p. 157-171.

Saunders R. (2014). Therapeutics. In: Meredith A., Lord B. (editors). BSAVA Manual of Rabbit Medicine. British Small Animal Veterinary Association, Gloucester, UK, p. 289-299.

Schnellbacher R.W., Divers S.J., Comolli J.R., Beaufrère H., Maglaras C.H., Andrade N., Barbur L.A., Rosselli D.D., Stejskal M., Barletta M. (2017). Effects of intravenous administration of lidocaine and buprenorphine on gastrointestinal tract motility and signs of pain in New Zealand White rabbits after ovariohysterectomy. American Journal of Veterinary Research 78, 1359-1371.

Varga M. (2014a). Anaesthesia and analgesia. In: Textbook of Rabbit Medicine. Second edition, Butterworth Heinemann Elsevier, Edinburgh, UK, p. 178-201.

Varga M. (2014b). Digestive disorders. In: Textbook of Rabbit Medicine. Second edition, Butterworth Heinemann Elsevier, Edinburgh, UK, p. 303-325.

Varga M. (2014c). The rabbit-friendly practice. In: Meredith A., Lord B. (editors). BSAVA Manual of Rabbit Medicine. British Small Animal Veterinary Association, Gloucester, UK, p. 64, 81-88.

Wenger S. (2012). Anesthesia and analgesia in rabbits and rodents. Journal of Exotic Pet Medicine 21, 7-16.

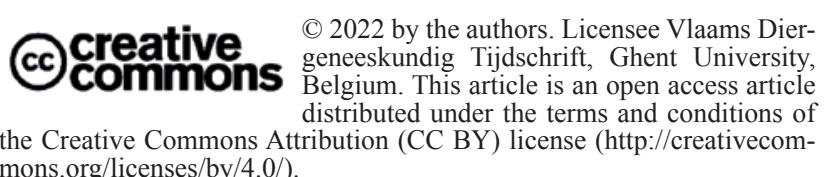

